\title{
Viewing the Revolution of the Modern Educational Teaching Methods from AR Educational Games
}

\author{
AiLing Chen \\ Department of Digital Arts \\ Dalian Neusoft University of Information \\ Dalian, China 116033
}

\author{
Ran Zhao \\ Department of Digital Arts \\ Dalian Neusoft University of Information \\ Dalian, China 116033
}

\begin{abstract}
Augmented Reality technology is a hot research topic at home and abroad in recent years, with the development of Internet game industry, intelligent mobile phone, Internet and other fields, the application of Augmented Reality technology has made great progress and development in the fields of business and digital educational games. This paper briefly introduces the development history, application status and development trend of Augmented Reality technology in modern educational games, focusing on the education method and model change issues in the background of Augmented Reality technology. It also introduces how to quantify and evaluate the learning effect of the users, and discusses how to enhance the practical experience of the learner in educational games and thus achieve the goal of "teaching goes together with pleasure".
\end{abstract}

Keywords-AR technology; application status; educational model; development trend; learning experience

\section{INTRODUCTION}

Augmented Reality (AR) is an important branch of virtual reality, it is a live direct or indirect view of a physical, real-world environment whose elements are augmented by computer-generated sensory input such as sound, video, graphics or data. It is related to a more general concept called mediated reality, in which a view of reality is modified by a computer. This new technology brings a more realistic visual effect, and a new environment with more scene information. It is a image rendering technique which integrates computer graphics, photoelectric imaging, fusion display, multi-sensor, image processing, computer vision and many other subjects.

The research of AR technology can be traced back to 1960s. In 1966, Ivan Sutherland, the father of computer graphics and virtual reality, invented a head mounted display, the appearance of the display is bulky, and the image system and the imaging effect are very rough, the AR technology of this period has been applied to business, always wandering in the field of scientific research. AR technology has developed rapidly in 1990s, the image navigation surgery operation room at MIT, the graphics and user interaction laboratory at Columbia University, Mixed Reality Laboratory in Japan, Germany Arvika Organization, Mixed Reality Laboratory in Singapore and many other famous research institutions in the world began to study the technology. China's AR technology research started late, and now the main research institutions are Beijing Institute of Technology, Beijing University of Aeronautics and Astronautics, National Defense University, Zhejiang University and Shanghai University.

\section{THE DEVELOPMENT AND APPLICATION OF AR TECHNOLOGY}

In recent years, the research and application of $\mathrm{AR}$ technology began to develop rapidly, but the commercial application due to the application in games. In 2001, the popular FPS game "Quake" (quake) was made a AR technical transformation, the release of AR-Quake is an expansion of the popular computer game Quake (Thor hammer). But it was only a technical test. In 2005, Anders Henrysson introduced ARToolKit to the Symbian system, based on the technology, the famous AR tennis game was published and it was the first collaborative AR application to run on mobile phones. In the same year, the game won the yearly award and the technical achievement award of the independent mobile games.

Since then AR has become one of the important functions of technology products, especially in the mobile AR industry, extending its functionality greatly, and it has been used more and more widely, and expanded to the new research areas, sush as the city planning, entertaining education, industria simulation, cultural heritage protection and so on. The applications with AR technology range from its initial location search programs and browsers to games, social network, education, lifestyle, and personal health care.

\section{APPLICATION STATUS AND DEVELOPMENT TENDENCY OF AR IN MODERN DIGITAL EDUCATIONAL GAMES}

At present, AR educational game has following types generally: First, role playing. For example, the science educational game "mad City mystery" developed by the Kurt D.Squire team of the school of education, University of Wisconsin at Madison. The player can choose to play the doctor, environmental experts, government officials and other different types of identity in the game, it aims at of training the learners' the ability of analysising scientific proof and the ability of logical exploring through the investigation for the deaths. Second, sensory experience. 
integrated the system laboratory of The University of Sao Paulo developed the music educational games -- Cen Virtual, the game helps people with learning disabilities to get music playing skills through music therapy, and improves their visual and auditory perception, motor coordination ability. Third, research and exploration (or simulation experiment). AR educational fun game--"Understanding endangered animals" developed by Juan at School of automation and computer science in Valencia Polytechnic University is in this kind. In addition, there is a game--"contact aliens" developed by the cooperation of Matt Dunleavv from Redford University and some colleagues from Massachusetts Institute of Technology and University of Wisconsin.

These different types of AR educational games are popular among learners, this is mainly because the AR technology has many advantages which other games or educational model do not have. First, AR has lots of wide and unique learning resources and materials, which can provide direct and scarce learning resources for learners, such as the reduction of prehistoric glacial age which was extremely cold, the simulation of high temperature and cosmic oxygen free space and other extreme environment which can not be reached, and also the preview of testing operation of some weapons of destruction. Second, improve the learner's concentration ability. With the diversity of presentation and interaction, AR can effectively stimulate all the senses of the learners and generate a high degree of immersion, which stimulates the learners' enthusiasm for learning. Third, the visual effect of AR technology can present the conceptual things, so that the learners can understand and accept them more easily. For example, it can transfer three-dimensional geometry, magnetic field, molecular motion, force and acceleration and other abstract nouns into visual information, which greatly enhance the learner's cognitive and understanding ability, and reduce their burden of learning.

As we can see, in the future the reation between AR technology and cognitive education will be increasingly close, which will continuously improve people's lifestyle, make things from urban exploration, tourism, security and rescue operations, moving and decorating the house to visiting a museum, shopping, history learning and customer service more convenient.

\section{EDUCATIONAL AND LEARNING MODEL WITH AR TECHNOLOGY WILL SUBVERT THE TRADITIONAL EDUCATIONAL LEARNING MODEL? TECHNOLOGY CHANGE TEACHING MODEL?}

\section{A. Comparative Analysis of Traditional Educational Learning Model and AR Educational Model}

The traditional learning model is mainly based on two basic theories - - constructivism and situated learning. Constructivism theory holds that learning is a process of updating information through activities. Learners learn knowledge and experience by taking part in activities. In the learning activities of constructivism, learners often take some initiative, unique and positive ways to solve problems.
Situated learning theory emphasizes not only the highly social nature of learning, but also embeds learning activities into the learners' life. In addition, it also emphasizes the dynamics of learning, ways of participation and diversity of the places. It believes that learners are also diverse, not just refers to individuals, but also social organizations and families. The connection with the material world is an important feature of situated learning. The value and advantages of AR Educational Games lie in imitating the real dialogue and environment which the real world can not do, and provide a thoughtful way to explore and think about the space of the problem and gain the intuitive experience. The advantages of training in ability are reflected in the following aspects:

One, collaborative learning. The design of AR game is based on the competition in the real world, and many themes require people with different skills to help each other, combining practical skills and appropriate tools to communicate and solve problems together. Two, learning based on problems. Taking challenges or problems as a starting point or clue, Games usually force participants to learn various skills, from reading to mathematics, from code to writing. Three, providing situational learning. Four, make rational use of information technology to create an incentive environment for students to master skills while solving problems.

In fact, education and games are inseparable. In a sense, all games have educational games. The educational characteristic of AR game is to challenge the new instructional thinking mode. Teaching innovation is not easy, learning in AR technology doesn't mean that we can avoid the teaching contents in teaching activities, and its learning activities also need to spend some time to repay. How can we design our teaching procedure? How to design classlearning activities is particularly important.

\section{B. Analysis of Class-Teaching Methods in AR Educational Games}

AR technology creates a complex knowledge landscape, and provideds a rich learning environment which provides navigation method for learning. Students can understand the complex problems and challenges, at the same time, they may make up the fragile relationship between learners and learning. Research in teaching method in this young field is still at the exploratory stage. AR educational game might improve and even subvert our educational model and teaching idea. From some point of view, AR technology is an effective tool for teaching, and teachers need to use the technology in their teaching, motivate and educate students through the games, use it to strengthen and integrate their own education and teaching, but it is not a panacea and can not guarantee to cure all diseases.

How to introduce the teaching content into class by using AR technology to achieve the expected teaching results has other problems and obstacles. One, how to match the effective tools--AR technology and teaching methods together in the current conservative textbooks. Second, it is necessary to select AR educational game types which are 
suitable for students' development so as to make AR technology adapt to the class. Three, how to control the classroom time with AR technology, and how to control the link between teaching sections and teaching content? Four, how to ensure that every student can achieve the expeced teaching effect?

\section{HOW TO QUANTIFY THE LEARNER'S LEARNING EXPERIENCE IN AR EDUCATION, OR PROVIDE A SOLUTION TO THE GAME.}

The scholar Juul proposed a good evaluation for the game, and its quantitative assessment must include the following six aspects: One, the rules of the game. Two, the varied and variable game results. Three, the value of the possibility game results. Four, the player's efforts and hard work. Five, the players who pay attention to the results. Six, the negotiable game results. Three of these are quantitative requirements for game results.

In AR games, the number of points doesn't seem to be so important. Setting appropriate learning goals is a key component of the design of the game itself. Because in many games, learners need to select and evaluate the information in the game and to maximize the rational use of the information. This is not measured by a practical, simple point or the score. Take the game "The Sims" published by The American Electr Arts Inc as an example, it is a computer game whose theme is simulating the lives of ordinary people. In this game, players can control the virtual figures' daily life, communication and community buildings. In the virtual world, the game imitates the real life, control the physical and mental demand, interact the relationship between their life and friends and neighbors closely. It often needs to make a choice, but to some extent the choice can be evaluated by the quality of the simple scores.

Compared with other traditional ways of education, the biggest advantage of $\mathrm{AR}$ education lies in the interaction produced in the process of education. The learning effect can also be examined in real-time interactive form, and learners can obtain timely learning feedback and guidance after playing the game or learning. Therefore, it is necessary to make a reasonable examination method, and the examination method can use many other types, such as the following:

One, pass-typed examination model. For example, in the design of team cooperation, the education aim of this type is to investigate the learners' self-learning ability through the collection of data and the ability of arrangement and analysis, to test the width of the learners' knowledge, to know their sense of teamwork cooperation and the communication ability in cooperation and so on.

Second, question and answer examinaion method. This method can be used to evaluate the learners directly. Such as the game--"Understanding endangered animals", it is a case of visual AR education. Learners can get the feedback immediately after their autonomous learning. it can give a specific quantitative description of the learners, such as what they have commanded and what have not, and provide some concrete solutions, learning methods and learning suggestions.

\section{How TO ENHANCE THE STUDENTS' LEARNING EXPERIENCE THROUGH AR EDUCATIONAL GAMES?}

First of all, it lies in the real experience of AR educational game, the research scholars, Self and Resnick, in this field proposed four different recommendations in the description of what is veracity in the learning activities. One, the connection between materials and activities and the extracurricular world. Second, teaching and evaluation (what should the students learn actually). Three, Subject research (what learning content does the learners in this stage want to know ). Four, the exploration of the foundamental practice method. Through game activities, the students are guided to a method or a variety of ways and even to more directions. Let learners sense the virtual world in the game, try the best to make the game personalized, rather like the old games, keep the learners and the roles matched through the game equipments, thus to produce a sense of reality and a feeling of being present. The more authentic the game experience is, the less virtual the game is, and the deeper the learner's learning experience will be.

The second lies in the innovation of AR educational games. One, the innovation of the game types and models. The complexity and the large-scale of the game is a trend, the simple and lively interface design and system in the previous game era can not meet the current demand of the game participants. In the future, the subjectivity of not only the educational game, but also any other game will be more prominent. Therefore, the game evaluation factors and indexs will be more and more, and the game development needs to be evolved and perfected. The design of the game type should be more characteristic, and the evaluation index should be more rigorous and professional.

It is worth noticing that AR's game design can not be separated from the following basic principles: First, maintaining the affinity, entertainment and interaction of education. Provide pleasure and satisfaction for the participants and engage them actively. Second, rules and objectives. Based on the intended teaching objectives, design the game sections, match the teaching content to game features, attract learners to participate using the power of the games. Third, adaptation. Provide appropriate challenges based on the different competence levels of the learners. Forth, results and feedback. No matter adopting which kind of evaluation method, always focus on the teaching objectives. When advanced development and game variants are needed, it is necessary to make the learning feedback of the experiencer and learners, and to develop the strict rules of the game and a detailed and precise evaluation standard. Fifth, providing motivation and exploring extension space, and stimulating the learners' creativity and the ability of further solving problems. Sixth, the design and presentation of the game sections should provide the plot of an emotion or a story, or conflict and confrontation, or competition and challenge.

\section{CONCLUSION}

According to the author's investigation and study, both the technology and the development research about AR 
abroad are like a hundred flowers in bloom, because AR education aims at not only the formal school education, but also facing different learners' age levels, professional knowledge, background and game experience, and the scope is rather broad and complex. The research of AR technology and its commercial development prospects are not the key points of this paper, so they are written just a little. This paper is focused on the connection between AR educational games and teaching in the process of teaching, aims at studying how to improve our teaching with the help of AR technology, rethinking, improving and further exploring the traditional teaching method, making up the deficiency in the traditional teaching model and method, not at negating or subverting the traditional education form, or blindly praising the AR educational game.

In addition, from the perspective of subject content, not all subjects are suitable for the AR educational game model, such as literature reading and writing, English grammar and rhetoric, or cooking, cocktails and so on, so we can not overgeneralize them, because any kind of education model has its limitations, even AR education game is no exception.

\section{REFERENCES}

[1] Xiangdong Chen,Zhongwang Jiang. "Application of augmented reality educational games ", Journal of distance education, 2012, p 68-72.

[2] Eric KLopfer. "Augmented Learning ", The MIT Press,Cambridge, Massaschusetts,London, England, June 2008, p13-155.

[3] Lifang Xu,Chengchi, Qizhang. "Research on educational games based on Augmented Reality", Journal of Xiangtan University(Philosophy and Social Sciences), 2015 Vol. 39, No2, p120-124.

[4] Qunzhi Meng. "Research on educational game design based on Augmented Reality Technology, Nanjing University of Aeronautics and Astronautics, March 2015. 